\title{
Research on the Community Intelligent Wireless Distributed Information Publishing System
}

\author{
Yan WANG ${ }^{1}$, Hai-zhou FENG ${ }^{1}$, Fang WANG ${ }^{2}$ \\ Jian ZHOU ${ }^{2}$ and Dan-tong LIU ${ }^{1}$ \\ ${ }^{1}$ Information Research Institute, Qilu University of Technology \\ (Shandong Academy of Sciences), Shandong, China \\ ${ }^{2}$ PetroChina Pipeline Storage and Transportation Co., Ltd. \\ Weifang Oil Pipeline, Shandong, China
}

Keywords: Intelligent Wireless; Distributed; Information Publishing System.

\begin{abstract}
Based on the research of the intelligent wireless distributed information publishing system in the new community, using wireless ad-hoc network technology, intelligent control technology, intelligent display technology, and regional distributed interactive information technology to the real-time public information, community information, advertising information in the community, and release the system can run independently in the community, and it can share the information in the community and network.
\end{abstract}

\section{Introduction}

The prosperity of the national economy, it has led to the vigorous development of various industries. Information breeds opportunity and creates wealth. With the increasing input and support from the state in the field of information technology, As well as the focus on community informatization in the 12th five-year plan, The innovative application of intelligent community will usher in the spring of development. Community intelligent wireless distributed information publishing system is an information publishing system for intelligent community application, independent intellectual property rights and advanced regional wireless self-organizing network.

This system is used for wireless distributed publishing of public welfare information, advertising information in the community. The system takes the physical scope of the community as the unit, and takes the family as the carrier to establish an information publishing platform combining with the wired and wireless network. The system adopts the most advanced short-range wireless two-way communication technology in the world, wireless self-organizing network technology, intelligent displaying technology, regional information controlling technology and network technology. It perfectly integrates with the public information network and the media industry. It plays a significant role in improving the intelligence level of the community, improving the interaction of community information and improving the quality of the community. It can establish an effective advertising distribution channel for the end customers. It provides the most direct means for the regional advertising information release and has the best pertinence.

\section{Design Scheme}

\subsection{Technical Scheme}

Community intelligent wireless distributed information publishing system realizes distributed information publishing and centralized information management. The system will take the community as the geographical unit and the every home as the carrier. It will build a community-wide coverage of the network architecture, which includes the management center, information center, information routing and information terminal Adopting advanced short-range wireless AD hoc network technology and Ethernet technology. The management center can be set up remotely. And it can manage the information of many communities. That system can realize remote centralized control of partition information. Control means include content management, 
authority management, user management, information audit, distributed and time-sharing information transmission of various intelligent community information publishing systems, etc. It can make the wide area control and regional implementation perfectly combination. The management platform is at the next level of the management center. It is composed of server and wireless network. It receives the information data of management center, and independently controls the information release in the community, which can be established in the property management office. Information routing is an information forwarding device to distributed and installed in the community. It is can effectively coverage the network and forward the reliable information in the whole community. The information terminal is a miniaturized multimedia information receiving and displaying device installed in the homes of the community. The functional diagram of the system is as Figure 1.

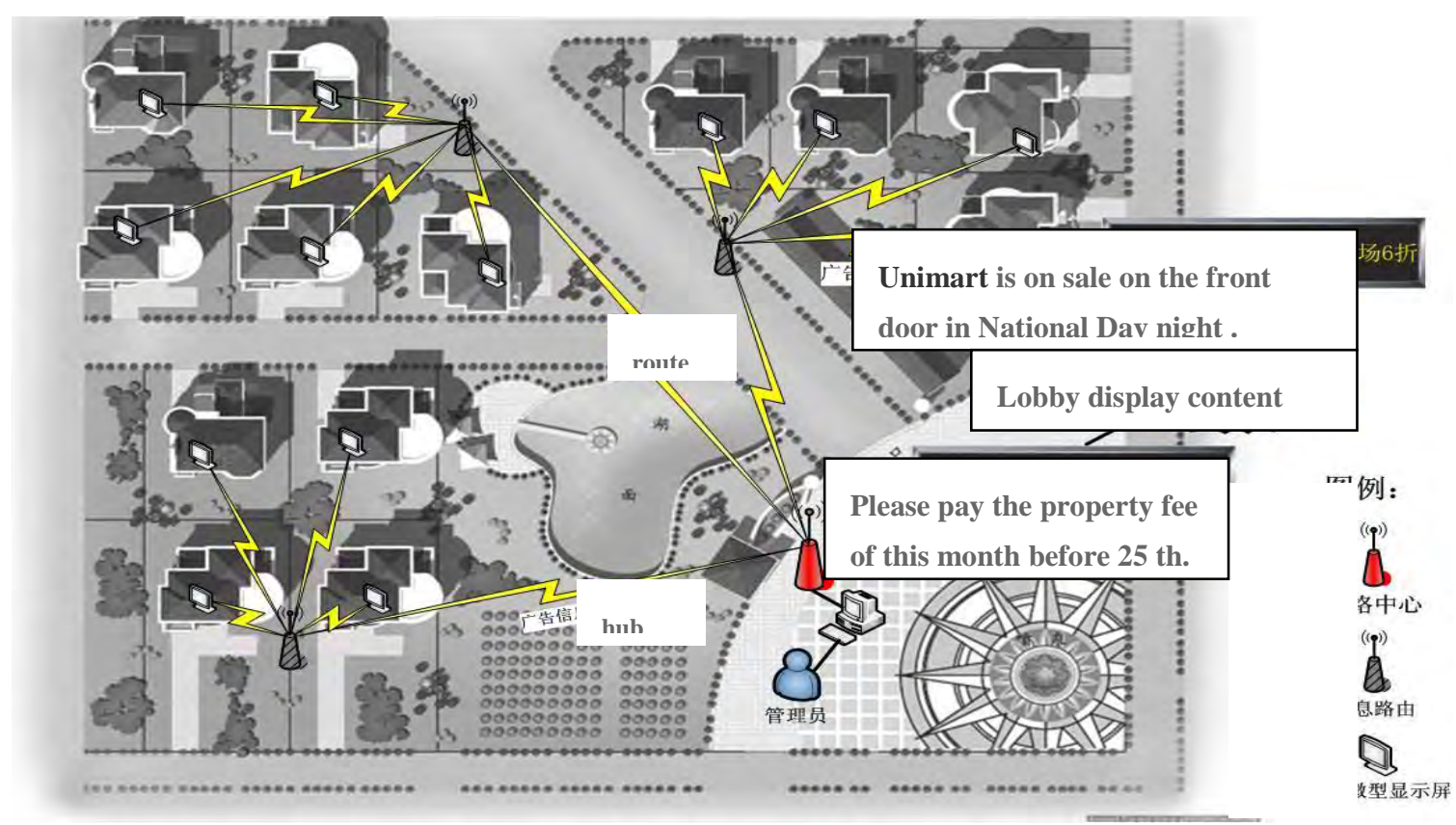

Figure 1. Function Diagram of the System

\subsection{Technical Implementation Plan}

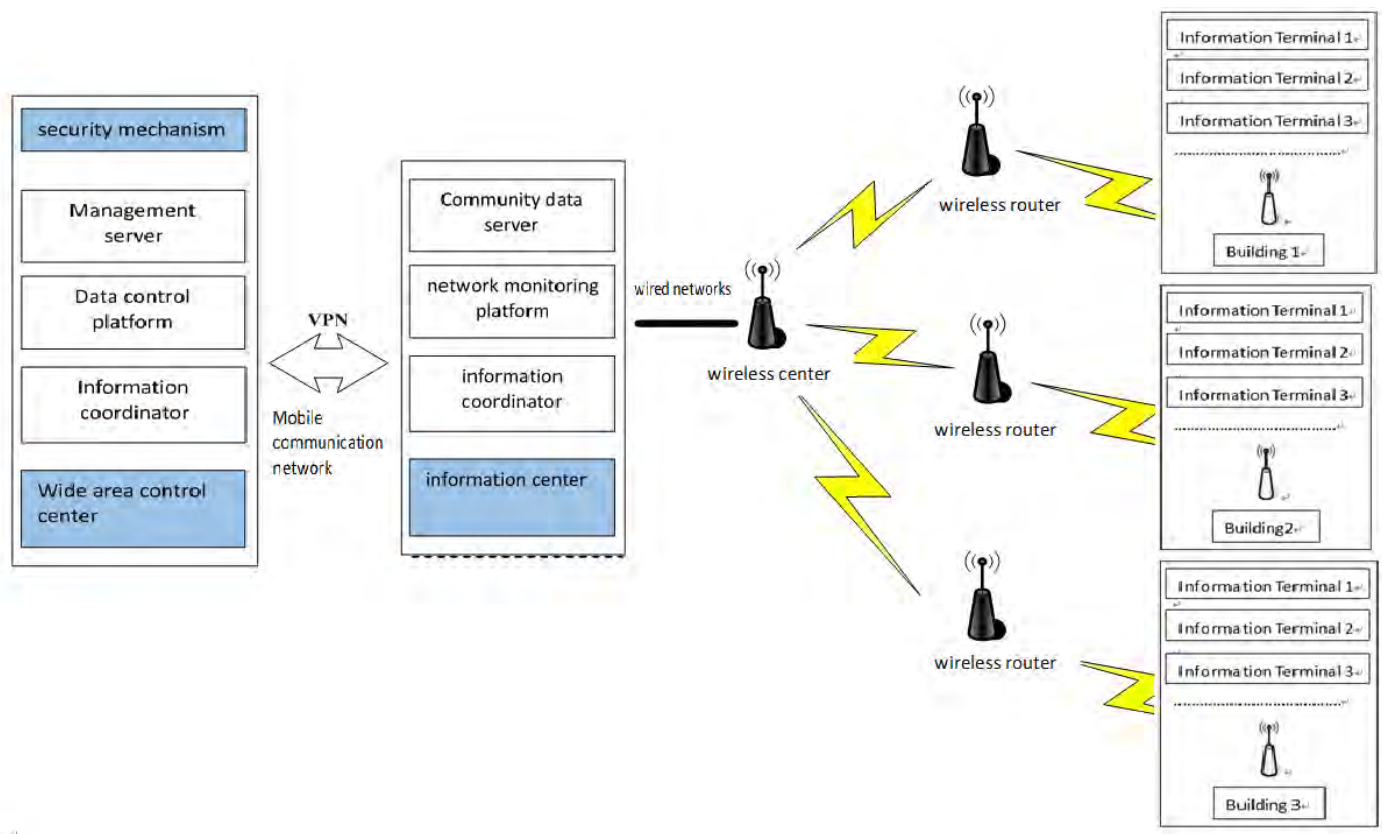

Figure 2. Design Scheme Drawing 
The system consists of wide area management center, community information center, information routing network and information terminal. The information distribution link is from management center to information center to information routing network to information terminal. It can manage, review, storage, release feedback the information.

1. Wide area management center is the core of the whole system. It maintains the operation of the whole system. It mainly consists of management server, data control platform and information coordinator. It manages and controls a large number of information of the community centers. It Audits, manages, data releases, feedbacks management the information. It controls security mechanisms

2. The community information center overall manages the information release system of the community. It includes community data server, network monitoring platform and information coordinator. The community data server receives the instructions and information data of the wide area control center. It a wireless network composed of sending information to information routing by $2.4 \mathrm{GHz}$ information coordinator. It receives the information and network status feedback from wireless network. It feedbacks the information to the network monitoring platform, and uses the data to maintain the operation of the network, statistics, storage, etc.

3. The community information routing network can used to wireless network coverage in the community. The wireless routing distributed in the community is connected to the information coordinator of the information center by the wireless self-organization. After obtaining the information, it distributes the information to the terminals.

4. Information terminals are installed on the wall in the home. It receives information data forwarded by rout. That data is displayed in real time through the LCD screen after analytical processing. It can receive the feedback information from the users. At the same time, it can send the information released and feedback to the management center through the network link. That is the two-way information release and feedback.

\section{Scheme Advantages}

1. The community intelligent wireless distributed information publishing system is based on the advanced 802.15.4 short-range wireless ad-hoc network technology. Without changing the existing wired network in the community, it can quickly and effectively establish the network architecture of terminal, route and center, and realize the wireless self-organization network with flexible network and seamless coverage.

2. Wireless technology has the characteristics of low power consumption, low bandwidth and high .Rf power is extremely low. It is especially for wireless information dissemination applications in the community and home.

3. System is a WAN and LAN integrated link that can be information management, transmission, distribution, processing, display through the management center, information center, routing information, information terminal. The system's characteristics include networking, directional, intelligent and professional.

4. The system adopts distributed technology, which can easily centralized management, distributed publish and wireless network two-way communicate. It is an optimal network scheme

5. The system is the special network. It is a high security.

6. The terminal adopts the OLED display technology of active luminescence. The characteristics include low power consumption, good display effect, fast response speed, stable image, high brightness, rich color and high resolution, etc.

\section{Concluding Remarks}

The community intelligent wireless distributed information publishing system communicates with the information terminal by wireless AD hoc network. It can multi-community, multi-network shares and distributes information by multiple control technologies, information technology. 


\section{References}

[1] Weifeng Song, Research on key technologies of intelligent transportation system information release system [D]. 2003 - Shanghai Jiao Tong University: Pattern recognition and intelligence system.

[2] Xiuqiao Li, research on real-time distributed ocean monitoring and information release system [D] Computer system structure, Shandong University, 2008.

[3] Sha Yang, Tian Hu. Model and research of distributed network multimedia information publishing system [J]. Digital Technology and Applications, 2012 (10).

[4] Guogang Zhou. Implementation and upgrade of wireless Led information publishing system based on Web [D]. Signal and information processing, Beijing University of Posts and Telecommunications 2014.

[5] Shukun Lai, Design and implementation of highway distributed network information release system [J]. China's Transportation Information, 2012 (9).

[6] Xinzhong Sun,Ying Song, Qingquan Li, Nianbo Zheng. LED integrated information publishing system based on INTERNET [J]. China's technological wealth, 2010 (14).

[7] Jianzhong $\mathrm{Xi}$. Internet of things parking space information dissemination and reservation parking equipment [J]. Computer Application, ISTIC PKU, 2014 (z1).

[8] Ping Guo, Yuanxin Ouyang, Zhang Xiong, Yuheng Liu. Design and implementation of distributed wireless information publishing platform [J]. Computer Engineering and Design, PKU, 2007 (20).

[9] Guogang Zhou. Implementation and upgrade of wireless Led information publishing system based on Web [D]. Signal and information processing Beijing University of Posts and Telecommunications, 2014. 